\section{ОПЫТ КОНСЕРВАТИВНОГО}

\section{МЕЧЕНИЯ ПАРОАОНТИТА ТЯЖЕАОЙ \\ СТЕПЕНИ С ИСПОАЬЗОВАНИЕМ \\ СОВРЕМЕННЫХ МЕТОАОВ \\ РАЗРУШЕНИЯ БИОПАЕНКИ}

\section{И TEХНОЛОГИИ PLASMOLIFTING}

Распространенность воспалительных заболеваний пародонта среди взрослого населения в мире остается на высоком уровне и не имеет тенденции к снижению [9].

При хроническом генерализованном пародонтите тяжелой степени (ХГПТС) в результате ряда деструктивных и функциональных изменений опорного аппарата зуба, одним из клинических проявлений которых является патологическая подвижность зубов, происходит наиболее серьезное прямое осложнение - потеря зуба, снижение жевательной эффективности, патология желудочно-кишечного тракта.

Также пародонтит тяжелой степени повышает опасность инфаркта миокарда в 3 раза [11]. Опасность ХГПТС обусловлена также немалой его ролью в развитии гипертонической болезни, ишемической болезни сердца, занимающих важные позиции в структуре причин инвалидизации и смертности населения [4]. В настоящий момент накоплено большое количество данных, доказывающих и подтверждающих взаимосвязь таких заболеваний, как сахарный диабет и сердечно-сосудистая патология с пародонтитом [7]. Многочисленные исследования с очевидной ясностью демонстрируют высокий риск развития ишемической болезни сердца и инсульта у лиц с хроническим пародонтитом [5].

Сегодня четко доказана роль микрофлоры в инициации и прогрессировании пародонтита. Предшествующие попытки контролировать заболевания пародонта были основаны на свойствах бактерий в лабораторной культуре и в их естественных условиях. Современные данные подтверждают существование пародонтопатогенных микроорганизмов в виде биопленки. Научные знания об этиопатогенезе пародонтита на сегодняшний день определяют пародонтальную микрофлору в составе биопленки в качестве доминирующего этиологического фактора.

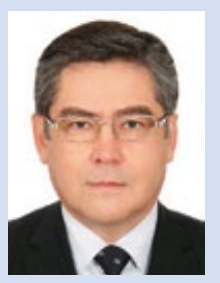

Буляков Р.T. д.м.н., проф., зав. кафедрой общей практики ИПО, ГБОУ ВПО Башкирский государственный медицинский университет, г. Уфа

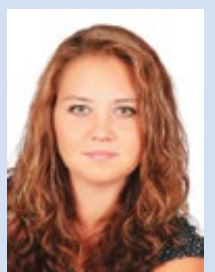

Сабитова Р.И. аспирант кафедры общей практики ИПО, ГБОУ ВПО Башкирский государственный медицинский университет, г. Уфа

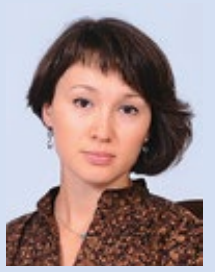

Гуляева О.А. к.М.Н., ассистент кафедры общей практики ИПО, ГБОУ ВПО Башкирский государственный медицинский университет, г. Уфа, oksgulyaeva@yandex.ru

Биопленка - это организованные в микроколонии, взаимодействующие микроорганизмы, сгруппированные при помощи вырабатываемого ими защитного адгезивного липополисахаридного матрикса. Сами бактерии составляют 5-35\% массы биопленки, остальная часть - межклеточный матрикс. Микроорганизмы в биопленке существуют и ведут себя не так, как бактерии в культуральной среде. К примеру, бактерия в биопленке может вырабатывать такие факторы вирулентности, которые она не продуцирует, будучи в культуральной среде и иметь резистентность к препаратам губительным для нее в лабораторной культуре. Матрица биопленки формирует экологическое убежище, эффективно защищающее бактериальные клетки, как от действия лекарственных препаратов, так и от иммунных защитных факторов макроорганизма. Микроорганизмы в биопленке более устойчивы к антибиотикам, антимикробным средствам и другим активным агентам. Механизм увеличения устойчивости бактерий к антибиотикам в биопленках обусловлен как ограничением проникновения антибиотиков через биопленку, так и генной изменчивостью у персистирующих в биопленке бактерий. Для достижения эффективности антибактериального или противомикробного 


\section{Резюме}

С целью поиска новых эффективных способов нехирургического лечения хронического генерализованного пародонтита тяжелой степени нами было проведено комплексное консервативное лечение 27 пациентов, включавшее помимо стандартной терапии следующую комбинацию: аппаратное удаление субгингивальной биопленки и технологию Plasmolifting.

Отсутствие клинических признаков воспаления, стабильный уровень значений гигиенических индексов в течение всего периода наблюдения и редукция глубины пародонтального кармана подтвердили высокую эффективность консервативной терапии пародонтита тяжелой степени разработанным нами терапевтическим комплексом.

Ключевые слова: воспалительные заболевания пародонта, пародонтит тяжелой степени, биопленка, Vector-терапия, Perio-Flow, Plasmolifting,консервативное лечение пародонтита.

CONSERVATIVE TREATMENT EXPERIENCE SEVERE PERIODONTITIS USING MODERN METHODS DESTRUCTION OF BIOFILM AND TECHNOLOGY PLASMOLIFTING

Bulyakov R.T., Sabitova R.I., Gulyaeva O.A.

\section{The summary}

With the purpose of search of new effective methods of non-surgical treatment of chronic generalized severe periodontitis we carried out a complex conservative treatment of 27 patients, includes in addition to the standard therapy following combination: hardware removal subgingival biofilms and technology Plasmolifting.

The absence of clinical signs of inflammation, stable level values hygienic indexes for the whole observation period and the reduction of the depth of periodontal pockets, confirmed the high efficiency of conservative therapy of severe periodontitis, developed by our therapeutic complex.

Keywords: inflammatory periodontal disease, severe periodontitis, biofilm, Vector-therapy, Perio-Flow, Plasmolifting, conservative treatmentof periodontitis. препарата в биопленке (применяемого как местно, так и системно) может потребоваться значительное увеличение концентрации препарата. Например, время проникновения ципрофлоксацина внутрь биопленки Pseudomonasaerogenosa увеличивается в 30 раз по сравнению со временем, требуемым для проникновения препарата внутрь одиночной клетки, а устойчивость к антимикробным препаратам возрастает в 50-1000 раз по сравнению со свободными и «флоттирующими» микроорганизмами.

На сегодняшний день в клинической стоматологии говорить об успехе пародонтальной терапии и рассчитывать на долговременность результатов проведенного лечения без физического разрушения биопленки не приходится.

Некоторые пародонтологи до сих пор со скептицизмом относятся к утверждениям о возможности эффективного лечения пародонтита без проведения хирургического вмешательства. Но в настоящее время консервативность и малоинвазивность, вторичная профилактика при лечении заболеваний пародонта приобретают все большую актуальность, особенно при пародонтите тяжелой степени, когда основным контингентом являются пациенты старшей возрастной группы либо пациенты с сопутствующей патологией, такой как артериальная гипертензия, атеросклероз, сахарный диабет и другими соматическими заболеваниями, то есть те, у кого высока вероятность наличия противопоказаний или низка вероятность успеха хирургического лечения.

По данным некоторых последних научных публикаций для устранения главного этиологического фактора пародонтита - биопленки зачастую нет необходимости в агрессивных хирургическихметодах, достаточно консервативной терапии. Об эффективности методов воздействия на поддесневую биопленку в комплексе первичного пародонтального лечения в литературе имеется много подтверждений. По данным ряда авторов эти методы, в частности из доступных российскому врачу ультразвуковая терапия с суспензией гидроксиапатита кальция - Vector (Durr, Германия) [8, 10, 12, 13] и воздушно-абразивная субгингивальная терапия взвесью глицина - Perio-Flow (EMS, Швейцария) $[2,6,14,15]$ или ClinproProfy (3MESPE, CША) [3] являются целенаправленными щадящими способами минимально инвазивной терапии, позволяющей добиться разрушения биопленки, что имеет решающее значение для успеха лечения.

В литературе имеются сведения об эффективности использования современных аппаратных методов разрушения биопленкии Plasmolifting [1] 

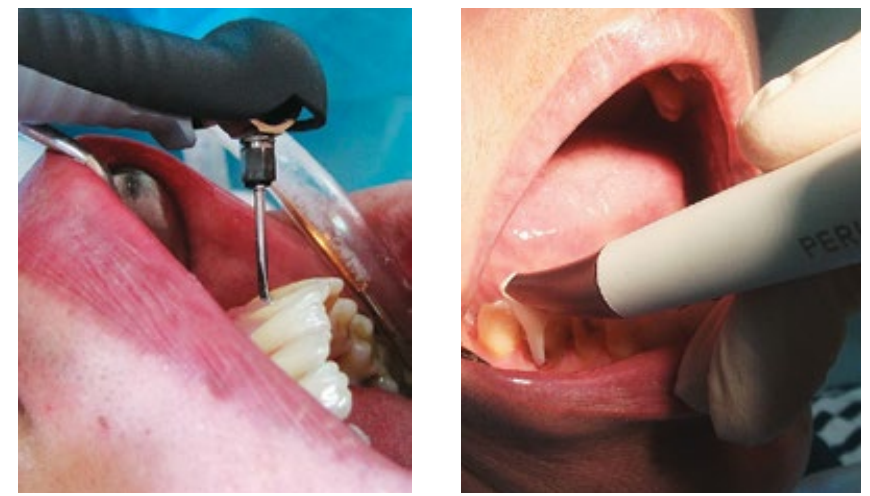

Рис. 1, 2. Обработка пародонтальных карманов методами Vector и Perio-Flow

для лечения воспалительных заболеваний пародонта, данных о применении же комбинацииэтих методовлечениядля пародонтита тяжелой степени нами не найдено.

\section{Цель исследования}

Оценить эффективность консервативной терапии хронического генерализованногопародонтита тяжелой степенис использованием нехирургических способов разрушения субгингивальной биопленки в комбинации с технологией Plasmolifting.

\section{Материалы и методы исследования}

Клинические исследования проводились на базе пародонтологического подразделения хирургического отделения АУЗ Республиканская стоматологическая поликлиника г. Уфы. В группу исследования было включено 27 пациентов с пародонтитом тяжелой степени в стадии обострения в возрасте 29-58 лет, 14 женщин и 13 мужчин. Из них у 66,7\% (18 человек) сопутствующим заболеванием являлась артериальная гипертензия, у $7(25,9 \%)$ сахарный диабет, у $22(81,5 \%)$ заболевания желудочно-кишечного тракта. Дефекты зубных рядов, восстановленные ортопедическими конструкциями, удовлетворяющими медико-техническим требованиям, имелись у 12 пациентов, 15 пациентам требовалось рациональное протезирование.

Оценка эффективности лечения проводилась на основе анализа заполняемой модифицированной нами пародонтограммы, включающей как клинические параметры: цвет, консистенцию десны, глубину пародонтального кармана (ПК)по 3 измерения с вестибулярной и небной поверхности восьми зубов у каждого из пациентов $(1.6,1.5$, $2.5,2.6,3.6,3.1,4.1,4.6$ - по два зуба в каждом секторе, при отсутствии - ближайший соседний), количество и характер отделяемого из ПК (при его наличии), подвижность зубов, так и результатов индексной оценки гигиены полости рта: индекса эффективности гигиены PHP (Podshadley, Haley, 1968), упрощенного индекса зубного налета на апроксимальных поверхностях API (Lange, 1977), индексной оценки состояния пародонта: индекса кровоточивости Muhllemann (1971) в модификации Cowell (1975), индекса Улитовского (по динамике значений индекса РМА).

Индексную оценку проводили до лечения, на 10-й день, через 6 недель, через 3 месяца, через 6 месяцев, через 1 год. Глубину ПК определяли до лечения, через 6 недель, 3 месяца, 1 год. Для оценки состояния костной ткани проводили цифровую ортопантомографию на аппарате TROPHYPAN eXpert DC, по показаниям прицельную рентгенографию. При необходимости консультировали пациентов у общих специалистов: терапевта, гастроэнтеролога, эндокринолога и др.

Всем пациентам было проведена комплексная пародонтальная терапия. В комплекс лечения включались мотивация и обучение пациентов гигиене полости рта с индивидуальным подбором средств гигиены и коррекцией гигиенических навыков, общая и местная противомикробная (антибактериальная), общеукрепляющая, противовоспалительная, десенсибилизирующая терапия, витаминотерапия, местная и общая иммунокоррекция, физиотерапия (лазер на начальном этапе №5 и дарсонваль №5 после снятия обострения при отсутствии противопоказаний), удаление неподлежащих лечению зубов, по показаниям депульпирование и шинирование подвижных зубов, избирательное пришлифовывание, рациональное протезирование.

В комплексе профессиональной гигиены для снятия зубных отложений применялся ультразвуковой метод (пьезоэлектрический аппарат Piezon 700 (EMS)), для удаления налета - воздушно-абразивный способ Air-Flow, для удаления субгингивальной биопленки была включена Vector-терапия (DurrDental) либо Perio-Flow-терапия (EMS) во 2-е (на 3-й день), 4-е, 5-е и 6-е посещение (рис. 1, 2).

Всем пациентам дополнили комплекс лечения использованием инъекционной формы тромбоцитарной аутоплазмы по технологии Plasmolifting.

Plasmolifting - метод получения и применения инъекционной формы тромбоцитарной аутоплазмы, разработанный Ахмеровым Р.Р. и Зарудием Р.Ф., основан на том, что содержащиеся в тромбоцитах факторы роста: тромбоцитарный фактор роста (PGDF-aa, PGDF-bb, PGDF-ab), трансформирующий фактор роста (TGF-b1, TGF-b2), фактор роста эндотелия сосудов (VEGF), фактор роста 
эпителия (EGF) ускоряют естественные механизмы восстановления тканей [1].

Для получения тромбоцитарной аутоплазмы используется собственная кровь пациента. Забор венозной крови проводился по стандартной технологии в специальные вакуумные пробирки Plasmolifting (рис. 3, 4), содержащие антикоагулянт гепарин натрия и специальный разделительный гель, позволяющий проводить фильтрацию плазмы и фиксацию эритроцитарного сгустка.

После забора крови пробирка помещалась в центрифугу EBA 20 (Германия) и центрифугировалась в режиме 3800 об/мин в течение 10 минут, в результате чего получали 4,0土1,5 мл плазмы, которая располагается в верхней части пробирки, затем идет разделительный гель, отделяющий эритроцитарный сгусток (рис. 5, 6).

Для инъекций использовались инсулиновые иглы. Области введения согласно рекомендаций авторов метода: в область зубодесневых сосочков и маргинальной десны из расчета 0,1-0,2 мл на 3 мм $^{2}$ и в область переходной складки 0,3-0,5 мл на 1-2 зуба (рис. 7, 8). В первое посещение проводили инъекции в двух сегментах с правой стороны (в 1-м и 4-м), во второе - через 7-14 дней с левой (во 2-м и 3-м). Каждому пациенту процедура проводилась 4 раза1-я и 2-я после базовой терапии (через 2-4 недели от начала лечения), 3-я и 4-я - через 6 месяцев после проведения субгингивальной терапии.

Статистический анализ данных осуществляли с использованием стандартных пакетов программ прикладной статистики. При описании количественных признаков использовали среднюю арифметическую (М), стандартную ошибку средней (m), при описании качественных признаков вычислялись относительные доли и стандартная ошибка доли. Для сравнения независимых групп по количественному признаку использовался критерий Стъюдента (t). Проверка статистических гипотез заключалась в сравнивании полученного уровня значимости (p) с пороговым уровнем 0,05 . При $\mathrm{p}<0,05$ нулевая гипотеза об отсутствии различий между показателями отвергалась и принималась альтернативная гипотеза.

\section{Результаты исследования и их обсуждение}

В день обращения пациенты предъявляли жалобы на кровоточивость десен при чистке зубов, припухлость десен, ноющую боль в деснах, боли при жевании, неприятный запах изо рта, подвижность зубов, нарушение жевания. У некоторых пациентов имели место жалобы на нарушение общего состояния: слабость, недомогание раздражительность, снижение аппетита.
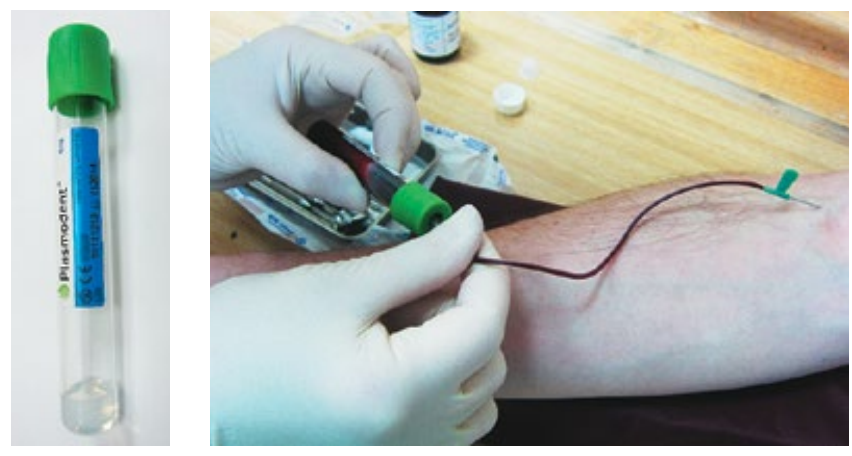

Рис. 3, 4. Пробирка Plasmolifting и процедура забора крови
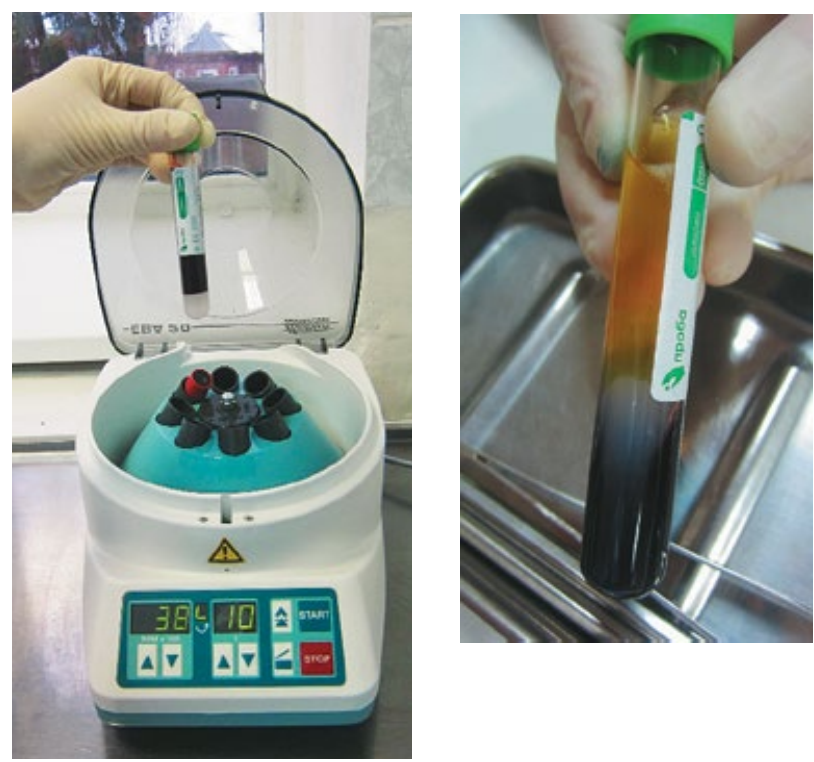

Рис. 5, 6. Центрифуга ЕВА 20 и полученная в результате центрифугирования плазма
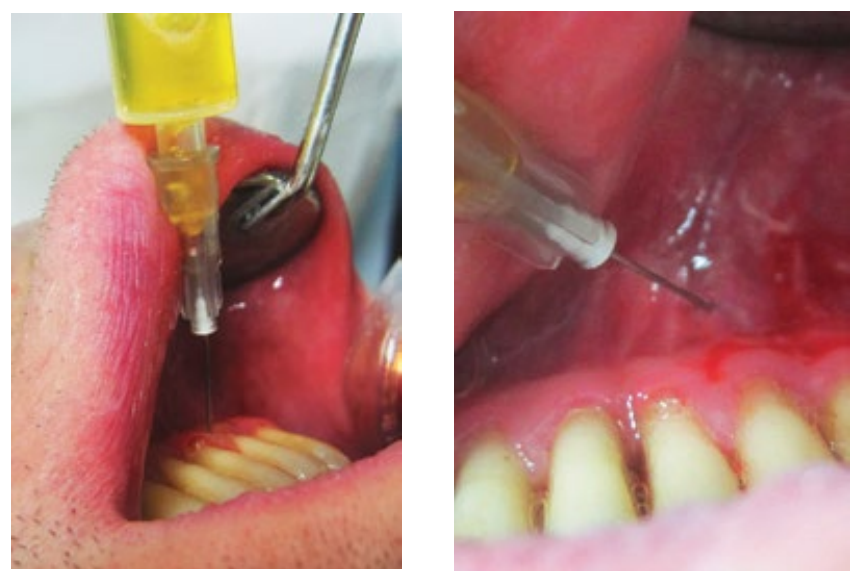

Рис. 7, 8. Инъекции аутоплазмы интрапапиллярно и в переходную складку

Объективно: в 1-е посещение клинически отмечались гиперемия, отечность, рыхлая консистенциядесны, глубина ПК составила в среднем 5,8土1,2 мм, из ПК серозно-гнойный экссудат, из некоторых карманов - разрастание грануляций. У некоторых зубов подвижность достигала II-ІІІ степени, име- 
лось смещение зубов, оголение шеек и частично корней зубов, наблюдалась гиперестезия. Кровоточивость десны по индексу Muhllemann имела среднее значение $2,91 \pm 0,11$. Выявлено значительное количество налета и зубного камня, в особенности поддесневого, гигиена полости рта была оценена следующим образом: значение индекса зубного налета на апроксимальных поверхностях API составило $78,21 \pm 7,31 \%$; значение индекса РНР также свидетельствовало о недостаточном уровне гигиены 2,51 $\pm 0,23$.

Уже в 3-е посещение (на 10-й день проводимого лечения) все пациенты отмечали значительное улучшение - у основной части пациентов жалобы отсутствовали. При анализе динамики уровня гигиены на фоне проводимого лечения у всех пациентов отмечалось уменьшение уровня гигиенических индексов API и PHР через 10 дней, закрепление результата в течение полутора месяцев после базового лечения в виде дополнительного небольшого снижения значений индексов и обратный их незначительный подъем через 3 и 6 месяцев в пределах норм оптимальной гигиены полости рта (рис. 9).

Улучшение клинического состояния десны отмечалось уже во 2-е посещение, придя к нормена 10 -й день по показателю кровоточивости $(<1,0)$, который достиг максимума через 6 недель $(<0,5)$ и практически на всем протяжении периода наблюдениясохранялся стабильным (рис. 10).

В результате проведенного лечения отмечена значительная положительная динамика по уменьшению глубины пародонтального кармана. Степень редукции глубины пародонтального кармана соста- вила 29,17\% (1,7 мм), так что у некоторых пациентов через год активной поддерживающей терапии глубина пародонтальных карманов составляла менее 5 мм (как при пародонтите средней степени). Рентгенологически отмечается уплотнение структуры костной ткани, незначительное уменьшение размеров деструкции межальвеолярных перегородок. Эффективность лечения по индексу Улитовского через год наблюдения - 91,24\%, 100\% пациентов переведены в фазу ремиссии заболевания.

\section{Выводы и рекомендации}

Отсутствие клинических признаков воспаления и стабильный уровень значений индексов API и PHР в пределах норм оптимальной гигиены полости рта в течение всего периода наблюдения, редукция глубины ПК в среднем на $1,2 \pm 0,5$ мм подтверждают высокую эффективность консервативной терапии хронического генерализованного пародонтита тяжелой степени при включении в комплекс лечения современных методов разрушения биопленки и технологии Plasmolifting.

Разработанная на основе клинических исследований и наблюдений схемадля практического применения, давшая положительные результаты у пациентов с хроническим генерализованным пародонтитом тяжелой степени: 1-я процедура субгингивального разрушения биопленки после профессиональной гигиены в течение противовоспалительного курса (на 3-7 день), 2-я процедура через 5-6 недель, 3-я процедура - через 2,5-3 месяца, далее через 4-5 месяцев. При достижени-

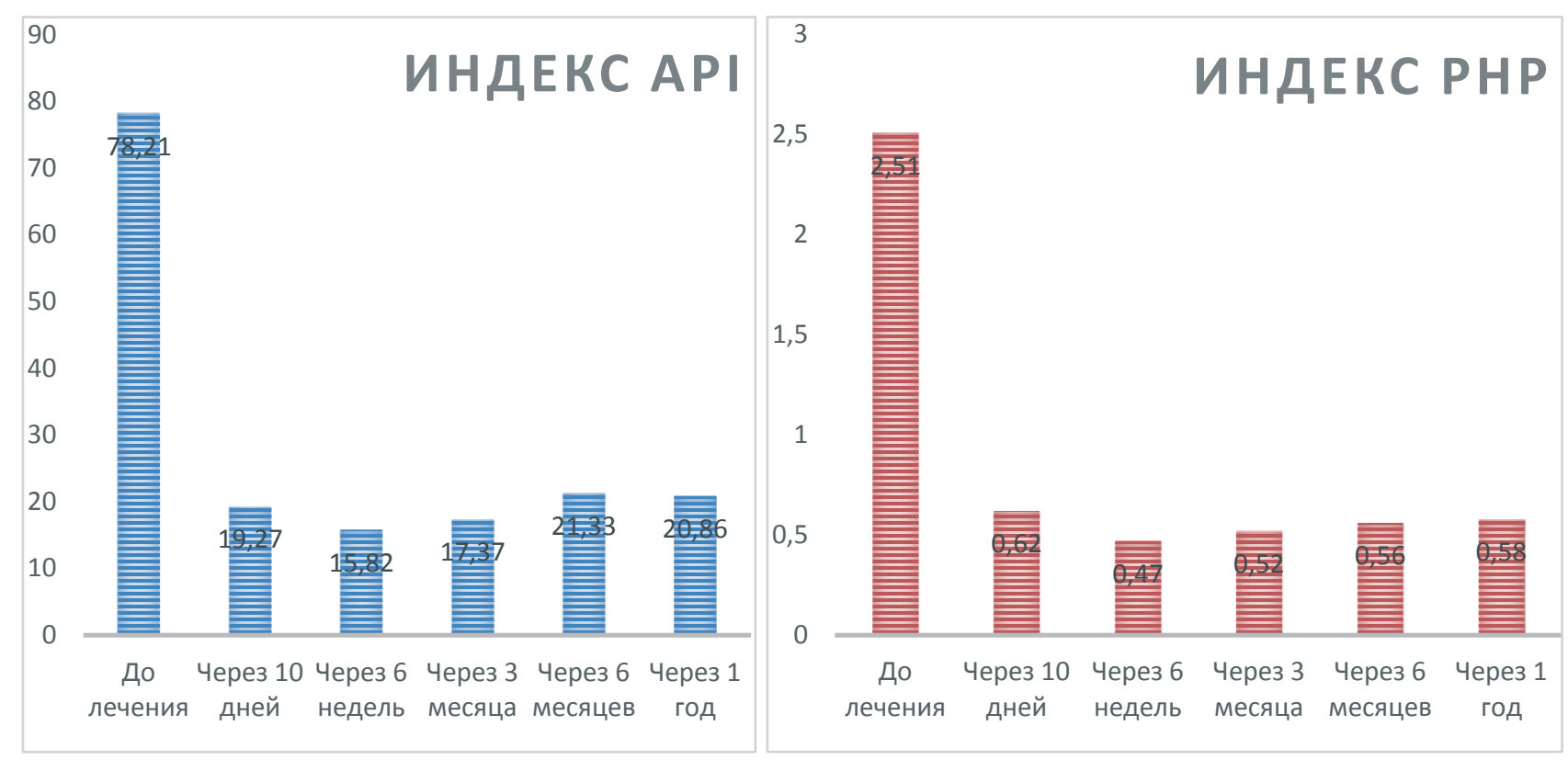

Рис. 9. Динамика индекса зубного налета на апроксимальных поверхностях АPI и индекса эффективности гигиены РНР в процессе лечения 


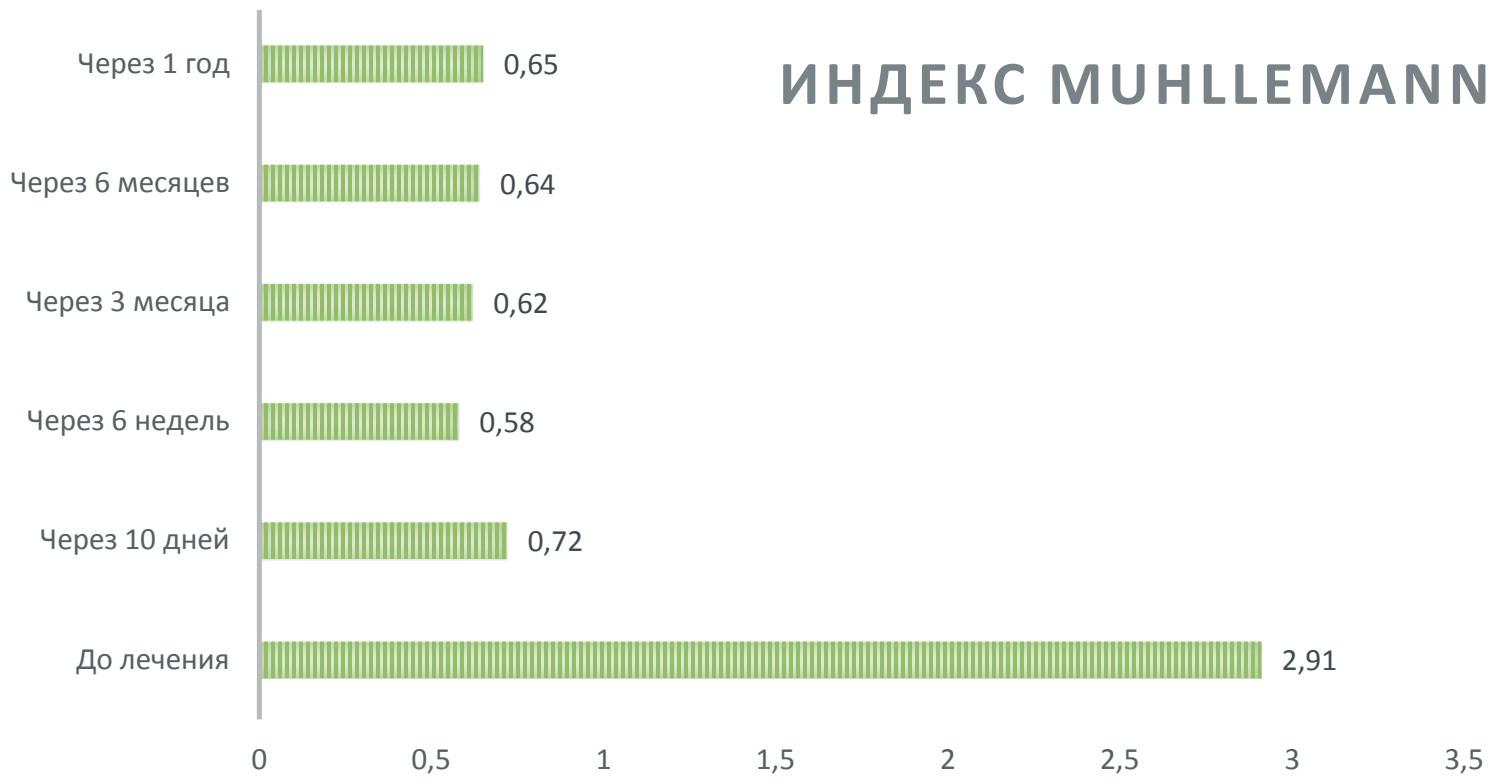

Рис. 10. Изменения индекса кровоточивости на протяжении проводимого лечения

истойкой ремиссии - поддерживающая субгингивальная терапия 1 раз в 5-6 месяцев. Plasmolifting проводится после базовой терапии, через 6 месяцев далее 1-2 раза в год в зависимости от индивидуального клинического случая.

\section{ЛИТЕРАТУРА}

1. Ахмеров Р.Р., Зарудий Р.Ф., Цыплаков Д.Э., Воробьёв А.А. Технология Plasmolifting - инъекционная форма тромбоцитарнойаутоплазмы для лечения хронических катаральных гингивитов // Пародонтология. - 2012. - №4. - С. 80-84.

2. Буляков Р.Т., Сабитова Р.И., Гуляева О.А., Чемикосова Т.С., Тухватуллина Д.Н. Новые возможности консервативного малоинвазивного лечения воспалительных заболеваний пародонта // Пародонтология. - 2013. - №1. - С. 55-59.

3. Волинская Т.Б. Дифференциальный подход в выборе порошка для воздушно-абразивной обработки зубов при лечении больных с воспалительными заболеваниями пародонта // Стоматология. - 2013. - №2. - С. 27 - 32.

4. Горбачева И.А., Орехова Л.Ю., Сычева Ю.А. и др. Роль сердечно-сосудистой патологии в формировании воспалительно-дегенеративных заболеваний пародонта // Пародонтология. - 2008. - №4. - С. 18-21.

5. Грудянов А.И. Взаимосвязь воспалительных заболеваний пародонта и рисков развития ишемической болезни сердца и атеросклероза // Клиническая стоматология. - 2011.-№ 4. - С. 34- 35.

6. Гуляева О.А., Буляков Р.Т., Чемикосова Т.С., Тухватулина Д.Н. Применение метода Perio-Flow в комплексном лечении пародонтита средней степени тяжести // Проблемы стоматологии. - 2012. - №2. - С. 14-18.

7. Елисеева А.Ф., Цимбалистов А.В., Шторина Г.Б. Роль смешанной инфекции в развитии хронического генерализо- ванного пародонтита и ишемической болезни сердца // Институт стоматологии. - 2012. - №2. - С. 78-79.

8. Орехова Л.Ю., Лобода Е.С., Щербакова Д.С. Антибактериальный и противовоспалительный эффекты пародонтальной терапии с помощью аппарата Vector // Пародонтология. 2011. - №3. - С. 31-37.

9. Пьянзина А.В., Герасименко М.Ю. Микроциркуляторные эффекты курсового применения флюктуофореза у пациентов с хроническим генерализованным пародонтитом средней тяжести // Стоматология. - 2013. - №4. - С. 34-36.

10. Рабинович И.М. Отдаленные результаты лечения воспалительных заболеваний пародонта с использованием системы Vector // Клиническая стоматология. - 2011. - №4. - С. 38-39.

11. Сарап Л.Р., Жиленко О.Г., Подзорова Е.А., Лесных И.В. Лечебно-профилактическая эффективность зубных паст на основе натуральных экстрактов у пациентов с воспалительными заболеваниями пародонта // Клиническая стоматология. 2009. - №3. - C. 40-42.

12. Цепов Л.М., Нестерова М.М., Голева Н.А. Способы финишной обработки поверхностей зубов и рецидивное камнеобразование у больных хроническим генерализованным пародонтитом // Пародонтология. - 2011. - №2. - С. 62-64.

13. Braun A., Krause F., Frentzen M., Jespen S. Efficiency of subgingival Calculus removal with the Vector-system compared to ultrasonic sealing and handinstrumentation in vitro.: Periodontal Research, 2005.

14. Flemmig T.F., Hetzel M., Topoli H., Gerss J., Haeberlein I., Petersilka G. Subgingival debridement efficacy of glycine powder air polishing /Journal of Periodontology 2007 v78 n6.

15. Petersilka G., Faggion Jr. C.M., Stratmann U., Gerss J., Ehmke B., Haeberlein I., Flemmig T.F. Effect of glycine powder air polishing on the gingiva J ClinPeriodontol, 2008. 